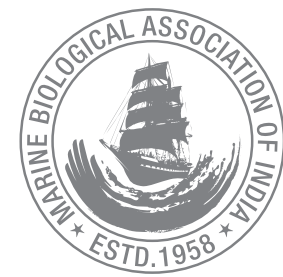

\title{
Assessment of fishers' perception in developing climate change adaptation and mitigation plans
}

\author{
Shyam, S. Salim*, T. V. Sathianandan, P. S. Swathi Lekshmi, R. Narayanakumar, P. U. Zacharia, \\ Pratibha Rohit, U. Manjusha, Bindu Antony, P. K. Safeena, Nivedita Shridhar, M. Ramees \\ Rahman, Rajani Jayakumar, Nimmy S. Kumar and C. P. Nimisha \\ Central Marine Fisheries Research Institute, P.B.No.1603, Kochi - 682 018, Kerala, India.
}

*Correspondence e-mail: shyam.icar@gmail.com

Received: 26 Nov 2014, Accepted: 03 Mar 2015, Published: 30 March 2015

Original Article

\begin{abstract}
Climate change is a global challenge today, with its impacts felt worldwide. The coastal regions around globe are more prone to the impacts of climate change than the inlands, fishing being one of the primary occupations of the coast, the fishermen community is the most vulnerable group to be affected by the climate change. Even with extensive scientific research in this arena there is a lacuna in finding a panacea to this existing problem. The objective of this study is to determine the scope of developing village level adaptation and mitigation plan for the community through a comprehensive analysis of the community perception on climate change impacts, vulnerability and existing adaptation mitigation strategies. In the chosen study villages of Ochanthuruth and Narakkal of Ernakulam district, the impact of climate change was felt on both resource and resource users based on a perception analysis made using comprehensive interview schedule administered across 300 households. The study revealed that the actual science and consequences of climate change impacts in a long run are not perceived well. The work suggests that concerted efforts in bringing about resilient community can be achieved through global understanding of the issue and coming up with area specific solutions with the inclusion of the much forgotten social factor- the stakeholders..
\end{abstract}

Keywords: Fisherfolk, climate change, awareness, adaptation, mitigation

\section{Introduction}

Coastal areas contribute significantly to the global economy by virtue of its natural resources, productive habitats and rich biodiversity. India with a long coastline of $8149 \mathrm{~km}$ supports almost 30 percent of its human population. Coastal fisheries are of immense importance as they provide livelihood opportunities for a large share of the population. The coastal state of Kerala is situated on the southwest coast of the Indian sub-continent, with an area of about 38,863 square kilometers and has a coastline of $589.5 \mathrm{kms}$, which apparently forms 10 percent of India's total coastline. Fisheries is a source of livelihood for the fishermen in Kerala, with fishing being an imperative part of the economy of the state (Kurien, 2001).

Coastal regions around the globe are dynamic in nature and are vulnerable to climate change impacts due to its very nature of population density and its proximity to the sea, consequently they are mostly affected by the changes in climate, such as sea level rise and monsoonal storms. The last century saw global rise of sea level contributing to increased coastal inundation, erosion and ecosystem losses with considerable local and regional variation. The late 20th century witnessed effects of rising temperature, including loss of sea ice, thawing of permafrost and associated coastal 
retreat, and more frequent coral bleaching and mortality (Nicholls, et al, 2007), thus making coasts highly vulnerable to impacts of climate change, where vulnerability can be defined as the degree to which a system is susceptible to, or unable to cope with, adverse effects of climate change, including climate variability and extremes (IPCC, 2007).

Though the physical exposure can significantly influence vulnerability for both human populations and natural systems on the coast, the lack of adaptive capacity is often the most important factor that creates a hotspot of human vulnerability. It is to be understood that adaptation costs for climate change are much lower than damage costs without adaptation for most of the developed coasts, even just considering only property losses and human deaths. Unless appropriate mitigation and adaptation measures are taken, climate change will frustrate fishers' efforts to achieve sustainable fish production and food security. However, developing such strategies will require information from the fishermen since the ability to adapt and cope with climate change depends on their knowledge, skills, experiences and other socio economic factors (Maharajan et al, 2011). Although, Kerala takes pride in the highest quality of life in the country as justified by human development indicators, the state's fishing community has largely been left out of the general development. The level of awareness is minimal which directly indicates the fishers' inability to correlate environmental changes consequent to climate change to their livelihood (Shyam et al, 2014a). The fact that the literacy level, educational attainment of fishers is much lower than that of the general population is a clear demarcation of the existing lacunae (Department of Fisheries, 2005).

Due to the lack of awareness about the big picture - The climate change, the fisherfolk are naïve in context to the source of the problem, which includes temperature rise, extreme weather events, reduction in fish catch over years, change in fish composition over the years and sea level rise. The process of providing right and comprehensive knowledge on climate change is the need of the hour and this can be achieved through a bottom up approach involving the primary stakeholders along with the community which will eventually position them to adequate climate change adaptation and mitigation by augmenting their traditional knowledge (Shyam et al, 2014b). This study considers local fishers as an integral part of the ecosystem, and their perception on the changing environment would play a vital role in formulating disaster management, adaptation and mitigation plans for the present and future. The objective of this study is to determine the scope of developing village level adaptation and mitigation plan for the community through a comprehensive analysis of the community perception on climate change impacts, vulnerability and existing adaptation mitigation strategies. As this sort of an assessment acts as a useful tool for planning local, national and global actions to respond to the impacts of climate change, climate variability, extreme events, and loss of biological diversity, thereby facilitating adaptive strategies through awareness building.

\section{Material and methods}

Ernakulam is the second most vulnerable coastal districts of Kerala which has got highest landings across the state and abodes more than 9.82 percent of total population (Marine census 2010). This study is based on the primary data collected from traditional fisherfolk households of selected coastal villages of Ernakulam district. The study areas were selected based on the Patnaik and Narain Method (2005) of social vulnerability assessment and the major parameters considered include number of fishermen households, number of traditional fisher families, number of BPL families, total fisher population, average family size, sex ratio, literacy ratio, adult child ratio, number of active fisher men etc. In order to compare adaptation and mitigation options across the different villages, Narakkal (highly vulnerable village) and Ochanthuruth (moderately vulnerable village) were selected (Table 1). Ochanthuruth village was found to be moderately vulnerable on account of better alternative avocation, available in comparison with Narakkal owing to the presence of many industries and development projects such as LNG (Liquefield Natural Gas) terminal in its immediate surroundings.

Table 1: Social vulnerability assessment matrix of Ernakulam district

\begin{tabular}{|c|c|c|c|}
\hline SI.No & Village & Score & Rank \\
\hline 1. & Ayyampally & 5.10 & 18 \\
\hline 2. & Azheekal & 7.53 & 7 \\
\hline 3. & Chellanam & 11.76 & 2 \\
\hline 4. & Cherai & 6.45 & 11 \\
\hline 5. & Cheriyakadavu & 4.39 & 20 \\
\hline 6. & Edavanakad & 7.00 & 10 \\
\hline 7. & Elamkunnapuzha & 7.50 & 8 \\
\hline 8. & Fortkochi & 3.83 & 21 \\
\hline 9. & Kandankadavu & 6.40 & 12 \\
\hline 10. & Kannamaly & 9.06 & 4 \\
\hline 11. & Kuzhuppilly & 5.91 & 16 \\
\hline 12. & Malipuram & 6.19 & 14 \\
\hline 13. & Manassery & 7.09 & 9 \\
\hline 14. & Maruvakkad & 6.00 & 15 \\
\hline 15. & Munambam & 9.70 & 3 \\
\hline 16. & Narakkal & 12.16 & 1 \\
\hline 17. & Nayarambalam & 6.38 & 13 \\
\hline
\end{tabular}




\begin{tabular}{llll}
\hline 18. & Ochanthuruth & 8.32 & 5 \\
\hline 19. & Pallipuram & 7.78 & 6 \\
\hline 20. & Pazhangad & 5.22 & 17 \\
\hline 21. & Saudi & 4.94 & 19 \\
\hline
\end{tabular}

A total of 300 households were selected randomly from both villages, with 150 respondent households from each village. Care was taken so that the respondents were equally distributed across the length of the coastline. The study covered the respondent households located within 500 meters from the shoreline. Personal interviews were conducted with the help of a pre-structured interview schedule, and were used after pre-testing. The primary data was recorded on gender, age, education and occupation. Data regarding fisher's perception on the impacts of climate change on resources and resource users, sources of information on climate changes, perception about adaptation and mitigation options were also collected. This study was conducted during April to July 2014. The study used the following methods of analysis to present the details in a logical manner, and to depict meaningful conclusions on community perceptions about climate change.

\section{Tools of Analysis}

\section{Percentage analysis}

Percentage analysis was used to examine the different variables pertaining to the respondents of the survey. Percentage analysis of respondents' age, gender and education was prepared for the analysis. Additionally respondents' perception on impact of climate change on resources and resource users, adaptation and mitigation options etc. were also analysed.

\section{Correspondence analysis for marine resource and resource users}

The present study employs the correspondence analysis in determining the association of respondents' level of awareness on climate change with a composite index of education, experience, proneness to natural disasters and availability of multiple income sources. In general, correspondence analysis is a statistical technique that is used by social scientists and behavioural researchers to explore the relations among multivariate categorical variables (de Leeuw, 2005; Hoffman \& Franke, 1986). Being a nonparametric statistical approach, the theoretical distribution cannot be compared to the observed distances. One of the benefits of CA is that, it can simplify complex sets into a simpler display of categorical variables while preserving all of the valuable information. In addition CA becomes useful due to its flexible data requirements (Hoffman \& Franke, $1986)$ and it focuses mainly on how variables correspond to one another and not whether there is a significant difference between these variables.

In order to analyse the data using correspondence analysis, certain factors are to be computed. Those include mass (Relative weight given to the response), distance (correlation between response) and the centroid (The weighted average response), which in turn gives inertia, where inertia can be described as weighted sum of square distances to the centroid. It can be represented mathematically by the following equation

Inertia $=\sum \mathrm{m}_{\mathrm{i}} \mathrm{d}_{\mathrm{i}}^{2}$

Where $m_{i}$ is the relative weight of the $i^{\text {th }}$ response, and $d_{i}$ is the distance of the $i^{\text {th }}$ response from the mean.

\section{Results and discussion}

The collected data were tabulated, analysed and are presented under the following heads.

\section{A. Socio-economic profile}

The socio economic characteristics of the respondents across the two villages of Ernakulam District viz., Ochanthuruth and Narakkal, was collected and computed. The parameters taken into consideration include, gender, age and educational status of the respondents. Majority of the respondents were male, constituting 70 per cent of the total respondents in Ochanthuruth and 74.51 percent in Narakkal. As the study coincides with the lean season most of the fishers were available in their households for the survey.

Age: The age wise distribution of the respondents indicated that majority of the respondents belonged to the elder group (>51) which constituted 43.33 per cent of the total respondents in Ochanthuruth and 49.33 per cent in Narakkal, this was followed by the middle age group (36-50) with 40.17 percent and 35.51 percent respectively. The younger age group of (15-35) respondents was represented least in the awareness survey with a total of 14.67 per cent in Ernakulam district indicated the dwindling interest of youngsters in fishing industry.

Education: Literacy rate of the respondents was found to be very high with 98 percent, however it was found that more than 60 percent of the respondents were only functional literates. This could be a caution in availing their educational skills in preparing adaptation \& mitigation plans. The respondents having primary and upper primary education, who possess the basic skills of reading, writing and calculating were categorized under functional literacy. 


\section{$B$. Impact of climate change on resources - perception analysis}

In the context of the study, resources indicate the fisheries sector, its allied activities and the inventories involved. In order to rank the perception of fisher households towards the different parameters affecting climate change on resources, respondents were asked to prioritise their perceptions on different factors namely shift in spawning seasons (SSS), migration of fishes (MoF), varied catch composition (VCC), catch reduction (CR), increased effort in fishing(IEF), alterations in fishing seasons(AFS), non-availability of regular species(NRS), occurrence of invasive species (OIS)), temporal shift in the species availability (TSA), loss in craft and gear (LCG) and depletion of farm inventories (DFI). Fig. 1 depicts the community perception on impact of climate change on resources. Accordingly fish catch reduction was perceived to be the most important impact of climate change by the respondent fisher households (88.32 percent) and they have been experiencing reduction in fish catch over year's aftermath of Tsunami. Paradoxically, real time data indicated

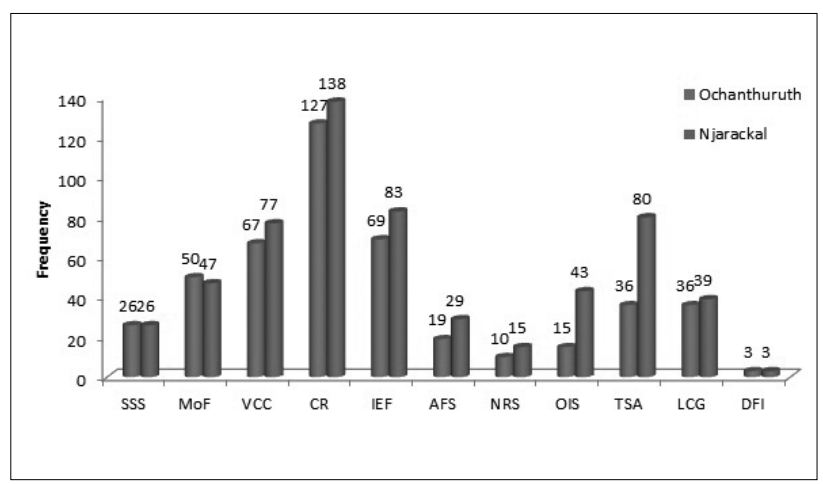

Fig.1. Community perception- Impact of CC on resources

that fish landings has not reduced much in the recent years. However, it is true that due to the increase in mechanisation and motorisation in fisheries sector, share of traditional fisherfolk is getting reduced and not solely because of climate change impact.

Secondly 50.61 percent of the total respondents were of the opinion that fishing effort has increased over years in congruent with the reduction in fish catch. Yet again it is very difficult to relate the increased effort in fishing with change in climatic conditions only. Other factors like mechanisation and increased competition in fishing sector also has to be considered as the reason for it. Moreover the very nature of traditional methods of fishing limits the scope of extending fishing effort and area, making the resource users especially traditional fisherfolk more vulnerable among the community.

Changes in fish catch composition over years were also perceived as the impact of climate change by 48 percent of the respondents including 22 percent from Ochanthuruth and 26 percent from Narakkal. According to some respondents many species like pomfrets, shark, ray fish, sardine and mackerel were only available in small quantity or not available now. Interestingly sardine which is known as "Kudumbampularthi", the most abundant species available for consumption for the community in the past, is also not readily available now for consumption even to the fisher folk especially to the traditional community, magnifies the issue of food security. Moreover, the issue of food security aggravated due to the current employment pattern of fishermen. Many are not willing to make a temporary shift from their traditional employment even in the lean period. In addition, the increase in saline water intrusion is limiting the scope of homestead agriculture which also contributes to the food security issue.

Many fisherwomen stated that they have experienced a change in taste for the fishes available now, especially for sardine and. Many voiced their opinion that the sardine available now is having very less amount of oil content and the availability of broodstock sardine vary between seasons. Another remarkable impact perceived by the 19.6 percent of the fisher folk is the occurrence of invasive species. They also stated that the number of puffer fish which is caught while fishing is very high nowadays, than ever before and it has led to huge loss to the traditional fishermen (season) as it damages the fishing gears.

\section{Impact of climate change on resource users}

There is a close association between climate change issues affecting the fishery resources and resource users. The perception of climate change on resource users is depicted in fig. 2. In order to rank the perception of fisher households towards the different parameters affecting climate change on resources, respondents were asked to prioritise their

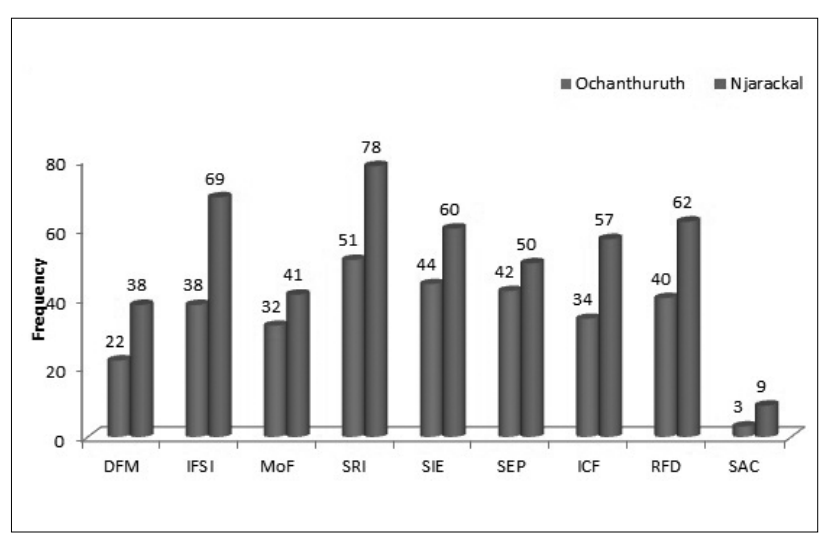

Fig.2. The perception of climate change on resource users 
perceptions on different factors namely displacement of family members (DFM), increase in food security issues(IFSI), migration of fishers (MoF), substantial reduction in income (SRI), seasonality in employment (SIE), shift in employment pattern (SEP), increased cost of fishing (ICF), reduction in fishing days (RFD) and shift in agriculture crops (SAC).

64 percent of the respondents (constituted by 78 percent from Narakkal and 51 percent from Ochanthuruth) are of the opinion that income level of fishers has decreased substantially over the years. They experienced substantial reduction in fishing days this year compared to the past. The reduction in fish catch will directly affect the employment patterns of the fishing community. Fishing labourers, who share one third of the total revenue of the catch, suffered heavily with substantial wage losses due to decrease in catch. They seemed to be in abject poverty, having no reserves to fall back upon. The traditional methods of fishing operations are gradually becoming non-profitable due to diminishing returns and are not sufficient to meet the basic operating costs. Hence a tremendous drop in the average number of fishing days was reported by 50 percent of the total respondent fisherfolk. This was experienced more by the respondents of Narakkal (62 percent) than the respondents of Ochanthuruth (40 percent). Some of the respondents have secondary employment opportunities which include net mending and weaving, supply and repair of fishing equipment and gear, boat building, running provision store, marketing, processing, transporting of fish and fish exports.

The seasonality of employment is a major problem reported by 51 percent of the fisherfolk including 60 percent from Narakkal and 44 percent from Ochanthuruth and they expressed their apprehension in the future food security. Fish stocks fluctuate seasonally in abundance and availability, leading to high and low fishing seasons. Sometimes when fish abundant seasons coincide with the seasonal low there is a dearth of marine fishes, in such cases availability of other food sources such as agriculture, inland fisheries can increase food security. The majority of fishers in the capture sector were seasonal workers, thus during the lean season the workers could return to inland farming or other works.

Nearly 46 percent of the fishers reported that there was a considerable change in the employment pattern (shift from fisheries to other sector). Disguised unemployment is rampant in all sectors since earnings from marine fisheries are not proportionate to the increase in fishers. This has instigated labour migration induced by the earning potential in the distant waters coupled with limited resources in their vicinity. Different employment migration patterns were observed among the respondents including temporary labour migration (marine sector to inland sector), inter-sectoral migration (fishery sector to other sector). Temporary migration is common in both these villages owing to the seasonality of fishing occupation. There were many inter-sectoral labour migrations reported in these villages and with many moving to the nearby cities in search of alternate avocation. They mainly sought jobs like construction, carpentry and masonry. In addition, majority of the younger generation were not interested to engage in their traditional livelihood options and hence the labour migration is expected to be high in the future. The full time fishermen in the marine sector find solace in the inland fishery sector or in other sectors which do not demand much skill (helpers /coolie workers) during the lean period for their sustenance.

Households that rely on a single source of income for their livelihood (eg. fishery) are more vulnerable to climate impacts than those who have diversified source of income, especially if they are highly dependent on sensitive resources. Diverse income sources may also indicate higher willingness to change occupations in the face of hazards or their impacts. For example, research has shown that households with higher numbers of income sources are more likely to leave fisheries sector than those with fewer income sources (Cinner et al., 2009). Fishery-related livelihood are complex, dynamic and adaptive. Some fishers engage in fishing full-time, all year round. More commonly though, people fish part time. They may take advantage of seasonally available riverine, coastal and off shore resources or they may fish-part time all through the year. This leaves to time to engage in other activities such as farming and rearing livestock. Fishing often shows this high degree of integration with other economic activities at the local level, such as agriculture, trading and the provision of labour. In general fisher communities are emotionally attached to their living environment as their livelihood is heavily dependent on sea. Still many cases of displacement and migration were observed in the villages due to multiple reasons including water logging and in search of alternate avocation. The availability of alternative and supplementary livelihoods, and the degree to which they are dependent on resources potentially impacted by climate, could influence the adaptive capacity of a household and its level of vulnerability.

The results indicated that there is a general tendency among the respondents to relate all the problems faced by the fishers to the climate change, as was revealed during the course of study. Though many problems and issues in fisheries sector could possibility connect with climate change, the causeeffect relationships could not define clearly as it is overlying or not be separated. Moreover results revealed that the respondents have not perceived the impact of climate change in its best way as they were not able to differentiate their general problems from climate change induced problems. 


\section{Level of awareness on significant impact of climate change on marine resources}

Correspondence analysis is employed to find out the association of respondents' level of awareness on climate change based on a composite index of education, experience, proneness to natural disasters and availability of multiple income sources. The above factors are given weights of 30 , 30,20 and 20 respectively and a composite index of 300 fishermen was computed and categorised as A, B and C. "A" indicates a low level composite index (low education, low experience, high proneness to disasters, and limited alternate avocation) and contributes to $72 \%$ of the total population, " $B$ " indicated medium level composite index and represents $15 \%$ of the population, while " $\mathrm{C}$ " indicated high level composite index (high education, high experience, minimum disaster proneness and numerous alternate avocation) and contributed to $13 \%$ of the population. The composite index values were plotted against awareness on different aspects of climate change, where the awareness level was categorised as Low, Medium and High based on ranking. The graphs (Fig. $3 \& 4$ ) explain each of the association in detail.

The sub-components of the awareness level on Marine resources includes, changes in spawning season of major fishes, migration of fishes, changes in catch composition, catch reduction, increased effort in fishing, shift in fishing season, occurrence of invasive species, unavailability of fishes which were caught in the past, damage to craft and gear and depletion of farm inventories.

Fig. 3 depicts correspondence analysis for the level of awareness on significant impact of climate change on marine resources

Table (2.1) shows the total variation of each dimension, which is calculated by dividing inertia of each dimension by variation as given in the table below. The first dimension (F1) has the highest explanatory ratio $(98.198 \%)$. It is seen that the explanatory ratio is less for the next (F2). The first two dimensions explain $100 \%$ of total variation.

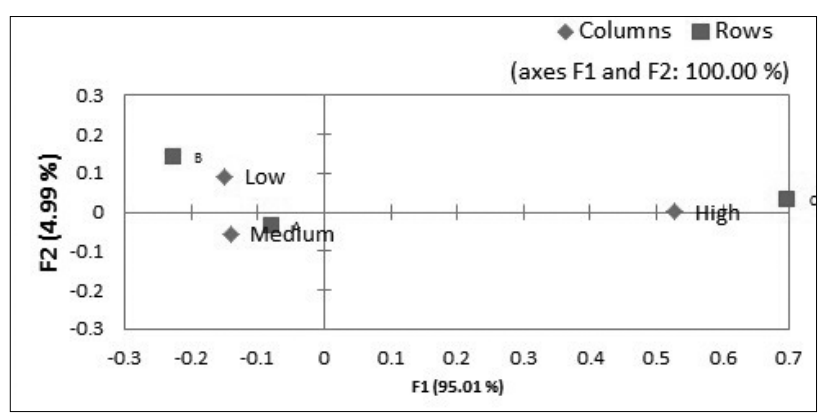

Fig.3. Correspondence analysis for the level of awareness on significant impact of Climate change on marine resources

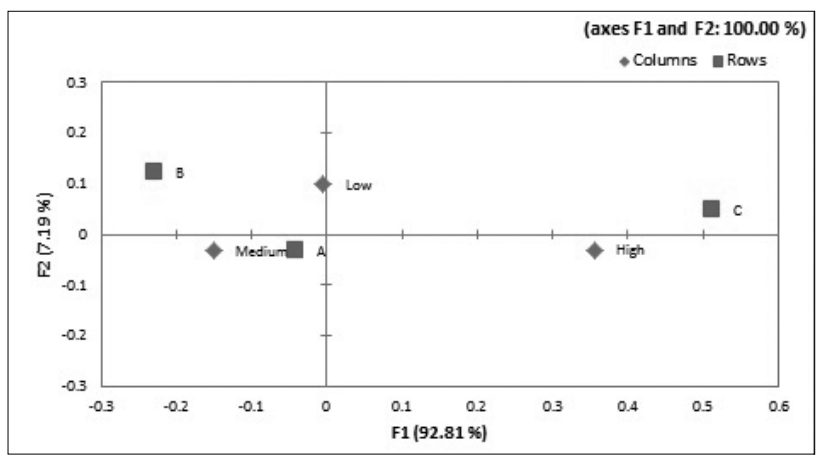

Fig.4. Level of awareness on significant impact of Climate change on marine resources users.

Table 2.1. Percentages of inertia in the correspondence analysis of impact of climate change on resources

\begin{tabular}{lll}
\hline & F1 & F2 \\
\hline Inertia (\%) & 95.010 & 4.990 \\
\hline Cumulative \% & 95.010 & 100.000 \\
\hline
\end{tabular}

Table 2.2 explains the contribution of rows in the correspondence analysis, where $\mathrm{C}$ determines dimension $\mathrm{F} 1$, which is the highest in the table.

Table 2.2. Contributions (rows) in the correspondence analysis of impact of climate change on resources:

\begin{tabular}{llll}
\hline & Weight (relative) & F1 & F2 \\
\hline A & 0.721 & 0.060 & 0.219 \\
\hline B & 0.149 & 0.101 & 0.751 \\
\hline C & 0.130 & 0.839 & 0.031 \\
\hline
\end{tabular}

Table 2.3 explains the contribution of columns in the correspondence analysis, where high level of awareness is determined by F1. Thus computing both tables 1.2 and 1.3, composite index " $C$ " determines high level awareness, which is also seen in the scatter graph.

Table 2.3. Contributions (columns) in the correspondence analysis of impact of climate change on resources

\begin{tabular}{llll}
\hline & Weight (relative) & F1 & F2 \\
\hline Low & 0.293 & 0.088 & 0.619 \\
\hline Medium & 0.493 & 0.126 & 0.381 \\
\hline High & 0.214 & 0.786 & 0.000 \\
\hline
\end{tabular}

\section{E. Level of awareness on significant impact of climate change on marine resource users}

Similar to the analysis carried out to understand the correspondence between climate change awareness and marine resources, an analysis was employed to find out the association of respondents' level of awareness on climate change on marine resource users, based on a composite index of education, experience, proneness to natural disasters and availability of multiple income sources. The above factors are given weights of 30,30, 20 and 20 respectively and a composite index of 300 fishermen was computed and categorised as A, B and C. "A" indicates a low level composite 
index (low education, low experience, high proneness to disasters, and limited alternate avocation) and contributes to $72 \%$ of the total population, "B" indicated medium level composite index and represents $14 \%$ of the population, while " $\mathrm{C}$ " indicated high level composite index (high education, high experience, minimum disaster proneness and numerous alternate avocation) and contributed to $12 \%$ of the population.

The sub-components of awareness of Marine resource users includes, displacement of family members, food security issues, migration of fisherfolk, fall in income level, seasonal employment, change in employment pattern, increased fishing cost, reduction of fishing days and shift in agricultural crops.

Table (3.1) shows the total variation of each dimension, which is calculated by dividing inertia of each dimension by variation as given in the table below. The first dimension (F1) has the highest explanatory ratio $(98.812 \%)$.It is seen that the explanatory ratio is less for the next, contributing to $7.188 \%$. (F2). The first two dimensions explain $100 \%$ of total variation.

Table 3.1. Percentages of inertia in the correspondence analysis of impact of climate change on resource users

\begin{tabular}{lll}
\hline & F1 & F2 \\
\hline Inertia (\%) & 92.812 & 7.188 \\
\hline Cumulative \% & 92.812 & 100.000 \\
\hline
\end{tabular}

Table 3.2 explains the contribution of rows in the correspondence analysis, where $\mathrm{C}$ determines dimension $\mathrm{F} 1$, which is the highest in the table.

Table 3.2. Contributions (rows) in the correspondence analysis of impact of climate change on resource users

\begin{tabular}{llll}
\hline & Weight (relative) & F1 & F2 \\
\hline A & 0.732 & 0.030 & 0.238 \\
\hline B & 0.144 & 0.184 & 0.672 \\
\hline C & 0.123 & 0.786 & 0.091 \\
\hline
\end{tabular}

Table 3.3 explains the contribution of columns in the correspondence analysis, where high level of awareness is determined by F1. Thus computing both tables 1.2 and 1.3, composite index " $\mathrm{C}$ " determines high level awareness, which is also seen in the scatter plot.

Table 3.3. Contributions (columns) in the correspondence analysis of impact of climate change on resource users

\begin{tabular}{llll}
\hline & Weight (relative) & F1 & F2 \\
\hline Low & 0.239 & 0.000 & 0.760 \\
\hline Medium & 0.532 & 0.295 & 0.173 \\
\hline High & 0.229 & 0.705 & 0.066 \\
\hline
\end{tabular}

The results of both the analysis, ie; Marine resources and resource users showed that composite index A ( low composite index) had medium awareness, while B (medium composite index) had low awareness and the level of awareness of composite index
C (high composite index) is was high (Fig.3 \& 4). This illustrates the situation, by showing that the section of the society with high education, experience, and multiple avocations are the best aware people, who can be the climate agents, while the respondents with low education and experience, who also lack alternate avocations are aware about climate change, though their knowledge is superficial. It is the people with medium level composite index who have low awareness, probably owing to lesser impact of climate change in their lives in comparison with low composite index respondents.

\section{Climate change Education Experience Matrix}

In continuation with the correspondence analysis, a climate change education experience matrix (Table 4) was developed to explain the results comprehensively.

Table 4. Climate change Education Experience Matrix

\begin{tabular}{lll}
\hline $\begin{array}{c}\text { Education } \\
\text { Experience }\end{array}$ & Low & High \\
\hline Low & $\begin{array}{l}\text { Laggards (Low education } \\
\text { and Low experience) }\end{array}$ & $\begin{array}{l}\text { Experimenters (High education } \\
\text { and Low experience) }\end{array}$ \\
\hline High & $\begin{array}{l}\text { Adapters (Low education } \\
\text { and high Experience) }\end{array}$ & $\begin{array}{l}\text { Change agents (High education } \\
\text { and high experience) }\end{array}$ \\
\hline
\end{tabular}

In the Education-Experience matrix of fisherfolk above, those who possess low experience as well as low education, namely laggards are the people not involved much in fishing activities or other developmental activities in general, and are considered the most vulnerable among the society. The people having high education and low experience are the ones with diverse job preferences other than fishing. They are the ones who have the potential to explore other livelihood options for their sustenance. Moreover the evidences from the field reinforces the fact that the people engaged in other occupations including masonry, carpentry and coolie work were mainly youngsters, having very low experience in fishing and with comparatively high level of education. In this study it was observed that the involvement of youngsters in fisheries activities is waning, they were not able to relate the changing climate scenario with fisheries sector and thus their awareness on climate change impacts on resources and resource users is negligible.

The next group of respondents has high experience but low education. In general they are vulnerable since they have poor education, but owing to high experience in fishing sector, they can contribute to Indigenous knowledge which is vital in adapting to local changes due to climate change. This section usually splurge their entire time and hone their skills in fishing and allied activities and have the probability to fall 
victim if their income from fisheries sector fails to meet their needs. Their experience in this sector helps them to relate upand-coming problems with changing climatic conditions.

The final category of people, are the ones with high level of education and experience can be categorized as the key informants. They are highly passionate about their fishing profession. Though they can make use of the multiple opportunities available for improving their income, owing to their higher level of education, they confine themselves to fishing occupation only because of their fervour to this sector. They are well informed about new developments in their area of expertise and hence there exists enormous scope to make use of them as Climate torch bearers.

Thus the society can be split into four divisions based on the context of climate change, where the groups can be named Change agents, Adapters, Experimenters and laggards. The Change agents, with the support of the Adapters and Experimenters and try to elevate the position of Laggards by bringing in better awareness on climate change. striking an equilibrium in the society.

\section{F. Suggested adaptation and mitigation options by the community towards reducing the impact of climate change}

The knowledge on climate change among the respondents of both these villages was very shallow and pertained to short term happenings. Within their limited knowledge they expressed their enthusiasm by suggesting adaptation and mitigation options in making the community resilient to climate change consequences. These options can be categorized into economic, social, environmental and developmental drivers and is explained below

\section{(i) Environmental measures}

Under environmental attributes, community's major priority was given to construction of (64.96 percent in Ochanthuruth and 84.78 percent in Narakkal) seawall along the shoreline to contain the impact of sea level rise. Since majority of the respondents were residing within 100 meters of shoreline, they believed that a seawall would protect their habitat and households from sea level rise and high tide. Paradoxically, it is a fact that seawall construction has an implication on the shoreline as it induces artificial sediment transport which leads to uncontrolled erosion and accretion.

\section{(ii) Economic measures/options for alternate avocation}

Options for livelihood diversification were desirable by 16 percent of the total respondents. It was observed that fishing was not an attractive and lucrative profession while considering the risks and uncertainties, especially to the youngsters; a clear shift to non-fishing activities like carpentry, masonry and coolie work was evident. Additionally, the existence of Kudumbasree self-help groups offers ample scope for initiating further income generation activities for the women fisherfolk. Mangrove planting was an option suggested by 50 percent of the respondents to reduce the impact of climate change. Knowingly or unknowingly many households have already adopted mangrove planting as a measure of biofence in protecting their habitat. Besides being a bio-fence mangroves have an incredible scope for developing alternate avocations, as it provides breeding ground for many fishes.

\section{(iii) Social measures}

All the registered fishermen are eligible for pension from Matsyafed after the age of 60 . According to 33.3 percent of the respondents from Ochanthuruth and 43.48 percent from Narakkal, pension was considered a good adaptation option for the traditional fisherfolk. Apparently, they felt that the amount they were getting was very minimal and that there was a necessity to increase the pension amount in accordance with the fluctuations in the living costs within the society. Thirty two percent of the total respondents requested for trainings and awareness programs on climate change issues, which would thereby widen their horizon of knowledge on the issues pertinent to their life situations. Furthermore the need of issuing early warnings/alerts concerning extreme weather events was also considered as a pivotal reason in reducing the hazard's impact on their lives and properties (31.9 percent). The need of rehabilitation during emergency situations was sought by 9 percent of the respondents. Many respondents recollected that the Santa Cruz school in Narakkal village was the chief place of rehabilitation during Tsunami event that occurred in 2004. Since Tsunami was an unexpected event, they did not have much preparedness to combat the catastrophe. Hence many respondents were of the opinion that community preparedness is vital in mitigating the negative impacts of any natural hazard or extreme events.

\section{(iv) Development drivers}

Better infrastructure facilities including good roads and transportation facilities, improved public health facilities and proper drainage were crucial in mitigating the impact of climate change according to 31.17 percent of the respondents. Improved safety and communication measures were also considered important in mitigating the climate change impacts according to 5.67 percent of the respondents.

Beyond the biased outlook on the global issue of Climate change, it is evident that the climate has been changing with 
implication on various ecosystems. The study establishes the fact that, though the effects of climate change are global, the possible solutions in terms of adaptation and mitigation measures are local. Coastal regions around the globe are witnessing the manifestation of the changing climate, which is impacting the major communities, i.e.; the fishing villages, who live by the sea and solely depend on it for their livelihood.

In the chosen study villages of Ochanthuruth and Narakkal of Ernakulam district, the impact of climate change was felt on both resource and resource users, where, resource primarily includes fishes and resource users indicates fishermen. Three hundred respondent households were chosen for the study. The chosen respondent community represents the community as a whole, which translates to the village, and further to the district and finally to the state. By extrapolating the methodology used similar kind of analysis can be carried out for other coastal states of India.

The impact of climate change has led to the study area in becoming vulnerable, based on the principle factors of sensitivity, adaptive capacity and exposure. The first step in accomplishing a society to become resilient to climate change is to bring in awareness on the same. One of the major findings of the study was that the fishers could not correlate the changes in their environment to climate change, but with further probing it was found that they were able to relate their problems in fisheries with changing climatic conditions. The coastal community could relate climate change issues in their life only in association with the Tsunami event that occurred in 2004. Since Tsunami had a devastating effect on their lives, properties and their livelihood, they could relate this disaster to the changing features of climate either as a starting point or as a cause. However climate change was seriously perceived by most of the fisher folk only in the past five years. Moreover the community's level of awareness on climate change impacts on resources and resource users, depend on various factors like education, experience, proneness to natural disasters and availability of multiple sources of income etc.

However awareness creation on climate change is a prerequisite to kick start any adaption and mitigation measure in any community. In order to have comprehensive adaptation and mitigation plans for the entire community, it is important to synergize the scientific and indigenous knowledge system of researchers and different stakeholders of the community. Moreover, it is relevant to take advantage of the key informants within the community to disseminate the need for long term and short term adaptation and mitigation options to combat the climate change impacts and thereby making the community more resilient to climate change. Furthermore, innovations would be possible in the areas like development of new fishing methods and fish farming activities, options for alternate avocations and livelihood enhancement program for the family, improved weather forecasts, energy conservation, provision of financial services, improvement of rural transportation infrastructure, investments in public healthcare and public welfare programs under different heads including environment measures, socio-economic measures and development drivers.

From the results gathered, it is clear that there is almost cent percent literacy, although when finely analysed, more than half the respondent population have only functional literacy. Thus, in order to induce awareness into the society, a three stage outlook is mandatory. The multistage includes meeting short term, medium term and long term needs in goal accomplishment.

The short term needs in all probable terms are urgent requirements, which need initiation and implementation without a time lag. The short term needs in this study, primarily delves into creating a society which migrates from just hearing about awareness to being aware. This would include improvement of knowledge, skill and attitude, through various workshops which would include stakeholders. The immediate needs also include physical measures, such as construction of scientifically engineered seawall in the study sites where there is severe erosion.

The medium term needs are those which need to be initiated instantly, but needs phase wise execution. The time taken to meet such needs might take few months to a year's time. Medium term needs include, creating climate knowledge, creating climate communities and community mobilisation in association with NGOs and SHGs. Medium term needs are more formal as in compared with short term needs. The long term needs are needs which are very vital for the society, but require a long time for accomplishment. Long term needs majorly involves displacement issues, where in the vulnerable fishers are provided with a safe yet economically sustainable household. The long term needs also include educating children of the community about climate change and other hazards, with specific attention to the science behind it as well as disaster risk reduction techniques. This stage involves policy interventions, which can be enforced for the betterment of the coastal communities.

Accomplishing these three stage plan would lead to the formation of climate change informed fishers, who are capable of equipping themselves to the changes, thereby making them less vulnerable and self-reliant. The research also has future scope to replicate the methodology for similar 
studies, with or without modification.

\section{Acknowledgement}

The funding support provided by Belmont Forum for carrying out the research study done as a part of the project "Global Learning for Local Solutions Reducing Vulnerability of marine dependent coastal communities", is gratefully acknowledged. The authors also express their sincere gratitude to the Director, CMFRI for the timely support and adequate facilities provided.

\section{References}

Cinner, J. M., T. M. Daw and T. McClanahan. 2009. Socioeconomic Factors that Affect Artisanal Fishers' Readiness to Exit a Declining Fishery. Conserv. Biol., 23:124-30.

De Leeuw, J. 2005. Review of Correspondence Analysis and Data Coding with Java and R. J. Stat. Softw., 14: 230-232.

Department of Fisheries. 2005 Marine fisheries of Kerala at a glance 2005.

Hoffman, D. L. and G. R. Franke. 1986. Correspondence Analysis: Graphical Representation of Categorical Data in Marketing Research. J. Mark. Res., 23: 213-227.

IPCC, 2007: Cimate Change 2007: the physical science basis. Summary for policy makers Contribution of working group I to the Fourth Assessment Report of the Intergovernmental Panel on Climate Change.
Kurien, J. 2001. The Socio-Cultural Aspects of Fisheries: Implications For Food And Livelihood Security: A case study of Kerala state, India. In: Goodwin, J.R.M. (ed) Understanding the cultures of fishing communities: A key to fisheries management and food security. FAO Fish. Tech. Pap., 401.p 196-217.

Maharjan, S. K., E. R. Sidgel, B. R. Sthapit and B. R. Regmi. 2011. Tharu community's perception on climate change and their adaptive initiations to withstand its impacts in Western Terai of Nepal. Int. NGO J., 6 (2): 35-42.

Ministry of Agriculture, Krishi Bhavan, New Delhi and CMFRI, Kochi 2012 Marine Fisheries Census 2010 Part II. 6. Kerala.

Nicholls, R. J., P. P. Wong, V. R. Burkett, J. O. Codignotto, J. E. Hay, R. F. McLean, S. Ragoonaden and C. D. Woodroffe. 2007. Coastal systems and low-lying areas. Climate Change 2007: Impacts, Adaptation and Vulnerability. Contribution of Working Group II to the Fourth Assessment Report of the Intergovernmental Panel on Climate Change, M. L. Parry, O. F. Canziani, J. P. Palutikof, P. J. van der Linden and C.E. Hanson, Eds., Cambridge University Press, Cambridge, UK, p. 315-356.

Patnaik, U. and K. Narayanan. 2005. Vulnerability and climate change: An analysis of the eastern coastal districts of India, Paper presented at the International Workshop on Human Security and Climate Change, 0slo, 21-23 June 2005, p.1-20.

Shyam . S. Salim, V. Kripa , P. U. Zachariah, Nivedita Shridhar and T. V. Ambrose, 2014a, Climate change Awareness, preparedness, adaptation and mitigation strategies: Fisherfolks perception in coastal Kerala, J. Aquat. Boil. Fish., 2: 670681.

Shyam.S. Salim, V. Kripa, P. U. Zacharia, Anjana Mohan, T. V. Ambrose and Manju Rani. 2014b. Vulnerability assessment of coastal fisher households in Kerala: A climate change perspective, Indian J. Fish., 61(4): 99-104. 